Article

\title{
Photo-Modulation of Single-Molecule Magnetic Dynamics of a Dysprosium Dinuclear Complex via a Diarylethene Bridge
}

\author{
Goulven Cosquer ${ }^{1,2, *}$ (D), Mritunjoy Kamila ${ }^{2}$, Zhao-Yang Li ${ }^{2,4, *}$, Brian K. Breedlove ${ }^{2}$ \\ and Masahiro Yamashita ${ }^{1,2,3,4, *}$ \\ 1 CREST, JST, 4-1-8 Honcho, Kawaguchi, Saitama 332-0012, Japan \\ 2 Department of Chemistry, Graduate School of Science, Tohoku University, 6-3 Aramaki-Aza-Aoba, \\ Sendai 980-8578, Japan; mritunjoy.kamila@gmail.com (M.K.); breedlove@m.tohoku.ac.jp (B.K.B.) \\ 3 WPI Research Center, Advanced Institute for Materials Research, Tohoku University, 2-1-1 Katahira, \\ Aoba-ku, Sendai 980-8577, Japan \\ 4 School of Materials Science and Engineering, Nankai University, Tianjin 300350, China \\ * Correspondence: cosquer.g@m.tohoku.ac.jp (G.C.); zhaoyang@nankai.edu.cn (Z-Y.L.); \\ yamasita.m@gmail.com (M.Y.); Tel.: +81-22-795-6547 (G.C. \& M.Y.)
}

Received: 30 November 2017; Accepted: 28 December 2017; Published: 2 January 2018

\begin{abstract}
A photo-switchable single molecule-magnet (SMM) with two Dy ions bridged by a bis-bipyridine-dithienylethene ligand was synthesised. Isomerisation effects on the magnetic properties were investigated. Particular attention was paid to the slow relaxation of the magnetisation in order to determine precisely the role played by the ligand. Photo-isomerization of the ligand induced a geometric rearrangement of the complex and an electronic reconfiguration. The changes were studied by solid and solution state magnetic measurements.
\end{abstract}

Keywords: dithienylethene; single molecule-magnet; photo-switchable

\section{Introduction}

Single molecule-magnets (SMMs) are a special class of compounds exhibiting slow magnetic relaxation and magnetic hysteresis at the molecular level. They show great promise for the construction of molecular scale devices with the ability to store or process information. SMMs that can be controlled by applying external stimuli, such as light, electric current, pressure, etc. will be useful for such applications. This can be accomplished by including multifunctional ligands [1-4]. Photo-switchable magnetic materials have become quite important in the field of high-density information storage media [5-7]. Photoactive dithienylethene derivatives (DTE) reversibly isomerizes between open and closed forms when irradiated with UV or visible light, respectively. The closed form is fully conjugated, whereas the open form is not.

Recently, we have reported a complex in which a photoisomerisable dicarboxylato DTE ligand bridges two Mn(salen) units [8]. The reversible photocyclization of the complex by irradiation with UV or visible light induces an on/off switching of the slow relaxation. In addition, complexes of $4 f$ ions or $3 d 4 f$ cores bridged by the dicarboxylato DTE have been reported [9-12]. Lanthanoid ions are more sensitive to the surrounding crystal field than $3 d$ ions are, and so, isomerization of the ligand should enhance the switching of the SMM behaviour. However, due to the high coordination degree of $4 f$ ions and their oxophilicity, only coordination polymers with weak modification of the magnetic properties after irradiation have been obtained.

To avoid this problem, we synthesised a new DTE ligand functionalised with two bipyridine coordination sites, instead of two carboxylato groups (Figure 1). This ligand was obtained 
in both open $\left(\mathbf{1}_{\text {open }}\right)$ and closes forms $\left(\mathbf{1}_{\text {close }}\right)$. Coordination to neutral Dy(hfac) 3 moieties (hfac $^{-}=$hexafluoroacetylacetonate) afforded a dinuclear complex with open ( $\left.\boldsymbol{2}_{\text {open }}\right)$ and closed forms $\left(\boldsymbol{2}_{\text {close }}\right)$. The effects of the isomerisation of the ligand on the magnetic properties of the ion were investigated in both solid and solution states.

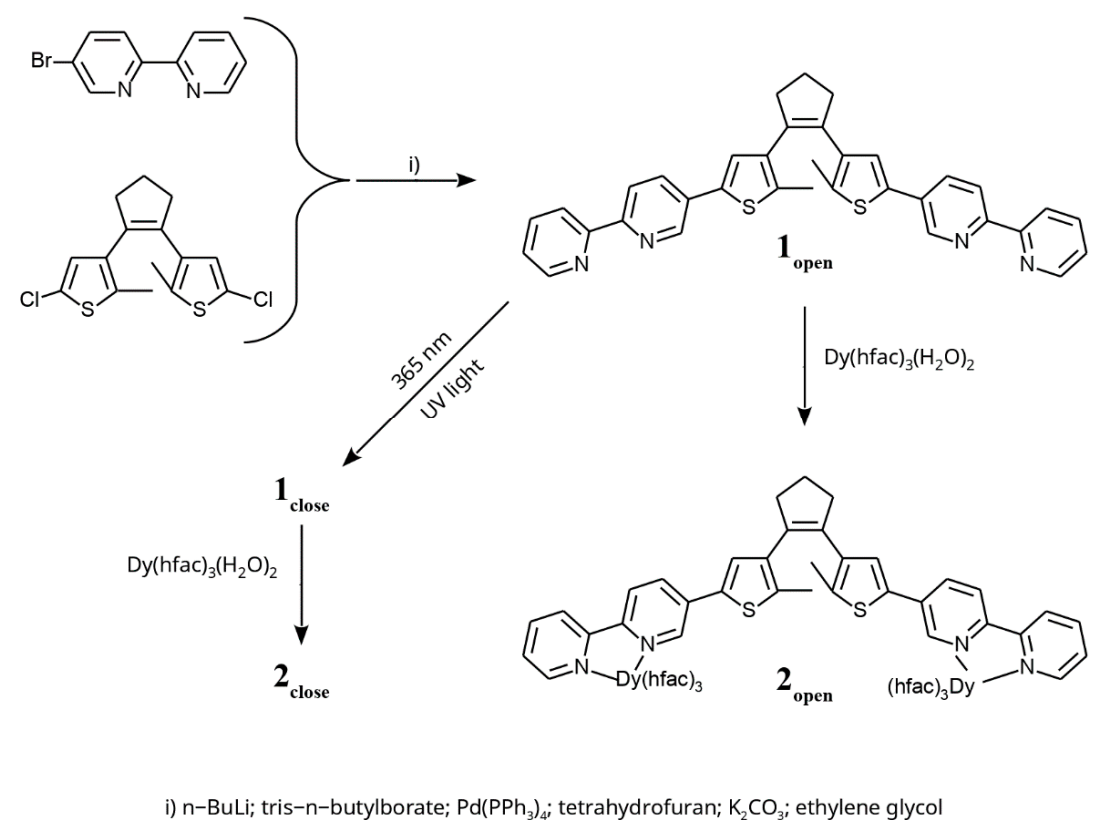

Figure 1. Synthesis diagram for $\mathbf{1}_{\text {open, }}, \boldsymbol{1}_{\text {close, }}, \boldsymbol{2}_{\text {open, }}$ and $\boldsymbol{2}_{\text {close }}$.

\section{Results}

A DTE-bridged bisbipyridine ligand was synthesized in the open form ( $\left.\mathbf{1}_{\text {open }}\right)$ and coordinated to Dy(hfac)3 units to form the dinuclear complex $\mathbf{2}_{\text {open }}$. By irradiating $\mathbf{1}_{\text {open }}$ with UV light, its closed form $\left(\mathbf{1}_{\text {close }}\right)$, and the corresponding complex $\left(\mathbf{2}_{\text {close }}\right)$ were obtained. The DTE core acts as a switch between the two Dy ions, turning on and off the electronic communication between ions of the complex.

\subsection{Structural Description}

The $\mathbf{2}_{\text {open }}$ crystallized in the monoclinic C2/c space group (Table S1). The complex, generated from the asymmetric unit by applying $C_{2}$ symmetry, was composed of two Dy(hfac $)_{3}$ units bridged by one DTE ligand and one heptane solvent molecule (Figure 2). The two Dy ions are equivalent by a $C_{2}$ rotation with the rotation axis passing through $\mathrm{C} 18$ and the $\mathrm{C} 16-\mathrm{C} 16^{*}$ double bond. The Dy ions are disordered on two positions (0.692 and 0.308 occupancies). The disorder was attributed to the steric hindrance of the solvent molecule. The Dy ions are coordinated to two nitrogen atoms from the bipyridine moiety of the DTE ligand and six oxygen atoms from three $\mathrm{hfac}^{-}$units with a distorted $D_{2 d}$ tetragonal dodecahedron coordination geometry (Table S2). The intramolecular distance between the two Dy ions was determined to be $17.021 \AA$. The $\mathrm{C} 14-\mathrm{C} 14^{*}$ distance of $3.569 \AA$ is short enough to photoisomerise the complex to its closed form [13]. Nevertheless, the presence of the solvent molecule prevent this isomerization (Figure S1).

The thiobipyridine moiety is almost planar with dihedral angles between the central and the two lateral rings of $11.26^{\circ}$ and $8.69^{\circ}$. This planarity allows $\pi-\pi$ interactions between neighbouring ligands with an average distance of $3.527 \AA$ and form a one-dimensional structure along the $c$ direction. The shortest intermolecular Dy-Dy distance was $9.047 \AA$. 
a)
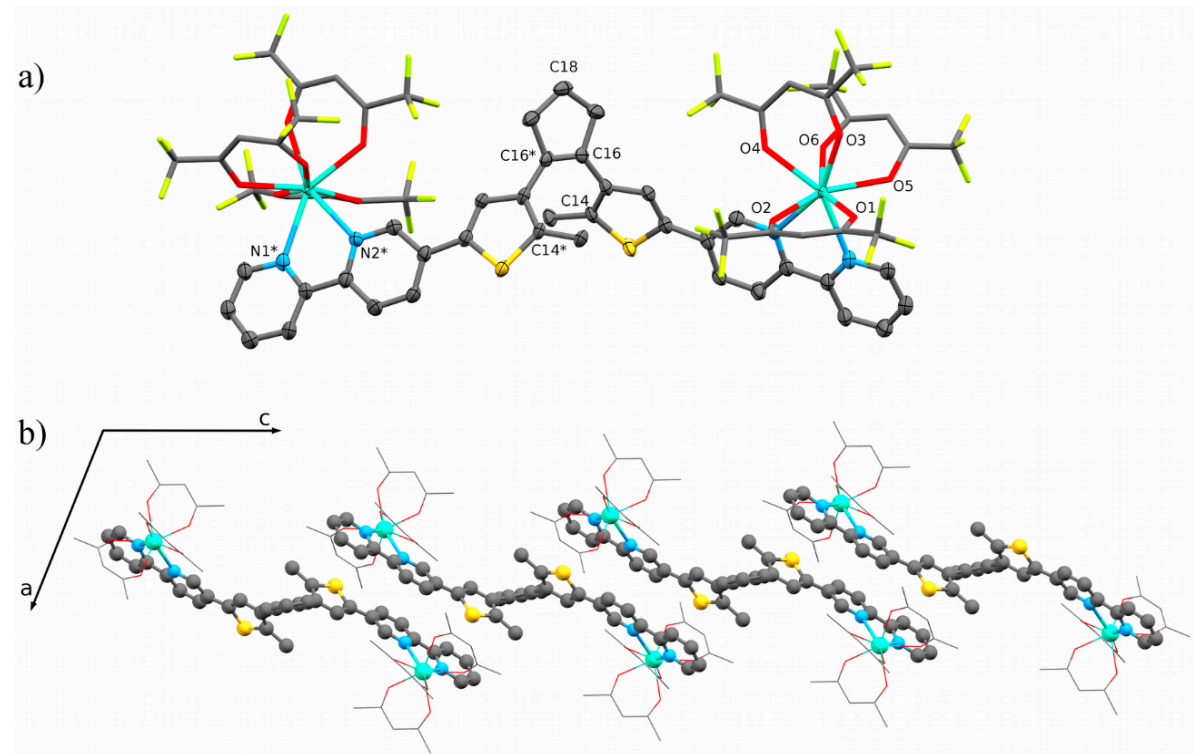

Figure 2. (a) Diagram of $\boldsymbol{2}_{\text {open }}$. Thermal ellipsoids for $\mathbf{1}_{\text {open }}$ are drawn at $30 \%$ probability. $\mathrm{H}$ atoms and solvent molecules are omitted for clarity; (b) $\pi-\pi$ chain structure of $\mathbf{2}_{\text {open }}$ along c direction.

The $\mathbf{2}_{\text {close }}$ crystallized in the triclinic $P \overline{1}$ space group. The asymmetric unit is composed of two Dy $(\mathrm{hfac})_{3}$ bridged by a DTE ligand and one heptane molecule as crystal solvent (Figure 3). Each Dy ion was crystallographically independent and was coordinated by two nitrogen atoms from the bipyridine group and six oxygen atoms from three $\mathrm{hfac}^{-}$moieties. The coordination geometry of both Dy ions was a distorted $D_{4 d}$ square antiprism, as determine by SHAPE 2.1 [14,15], and the intramolecular distance between the two Dy ion was $17.705 \AA$. The four carbon atoms C14, C15, C21 and C22 were disordered (0.51 and 0.49 occupancies). The closed form causes the delocalization of the $\pi$-electrons over the entire ligand, making the ligand planar with maximum dihedral angle between two adjacent aromatic rings of $14.29^{\circ}$.

a)
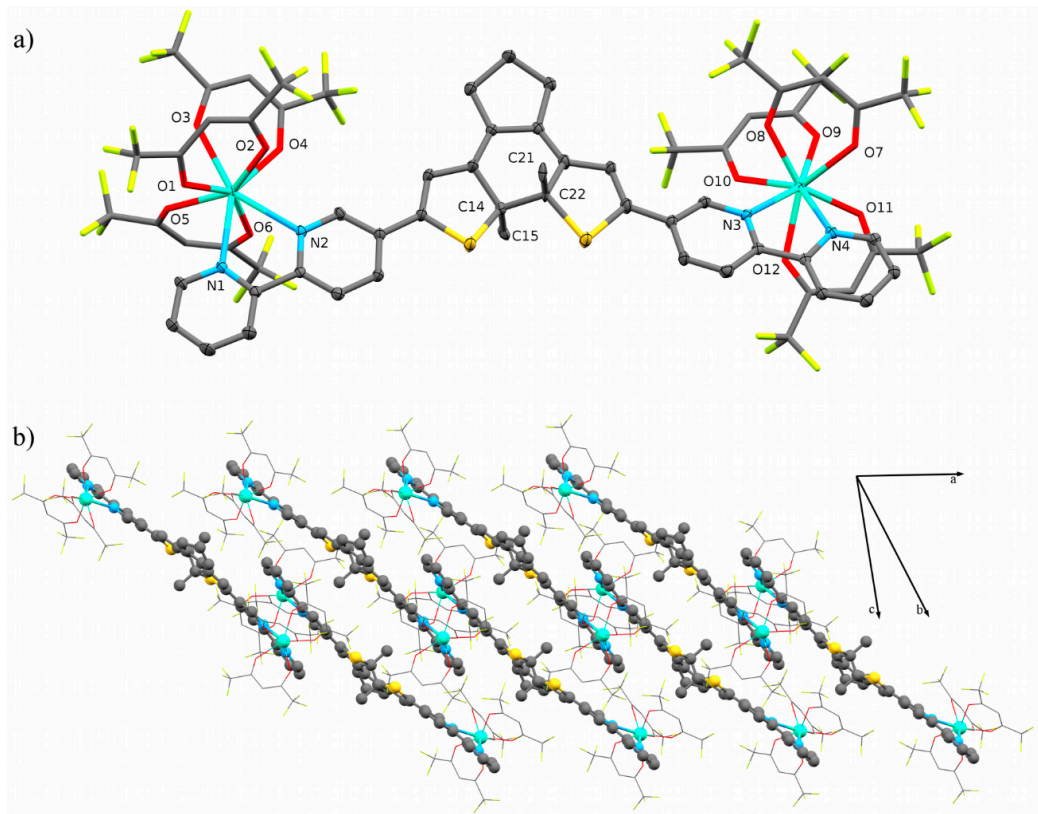

Figure 3. (a) ORTEP diagram of $\mathbf{2}_{\text {close }}$. Thermal ellipsoids are drawn at $30 \%$ probability. $\mathrm{H}$ atoms and solvent molecules are omitted for clarity; (b) $\pi-\pi$ chain structure of $\boldsymbol{2}_{\text {close }}$ along the $a$ direction. 
A dimer was formed through $\pi-\pi$ interactions between bipyridine rings of two neighbouring molecules with an average distance of $3.442 \AA$ without formation of extended 1D structure. The shortest intermolecular Dy-Dy distance was $8.606 \AA$. The photo-isomerisation from closed to open forms was not possible in the solid state due to the presence of heptane as crystal solvent (Figure S2) and/or $\pi-\pi$ interactions between the neighbouring ligands.

\subsection{Optical Properties}

Optical properties of the ligands and complexes were measured in $\mathrm{CH}_{2} \mathrm{Cl}_{2}$ solution (Figure 4). Photo-isomerisation of the compounds was followed using UV-Vis absorption spectroscopy in the solution state as a function of UV or visible light irradiation times. Before UV light irradiation, in the spectrum for $\mathbf{1}_{\mathbf{o p e n}}$, a strong $\pi-\pi^{*}$ transition band, which corresponded to an $\mathrm{S} 0 \rightarrow \mathrm{S} 1$ singlet intraligand (IL) transition, was observed around $340 \mathrm{~nm}$ [16]. Upon UV light irradiation, two new absorption bands appeared around 380 and $560 \mathrm{~nm}$ within $10 \mathrm{~s}$, and they were assigned to $\pi-\pi^{*}$ transitions of the "closed" form [11]. Upon irradiation with visible light, the initial spectrum was recovered within $35 \mathrm{~min}$. This longer photo-isomerisation time was explained by the larger delocalization of the $\pi$-electrons across the DTE core and the bipyridine rings due to the full conjugation of the ligand in its close form. Thus, the close form is more stable, and photo-isomerization is slower.

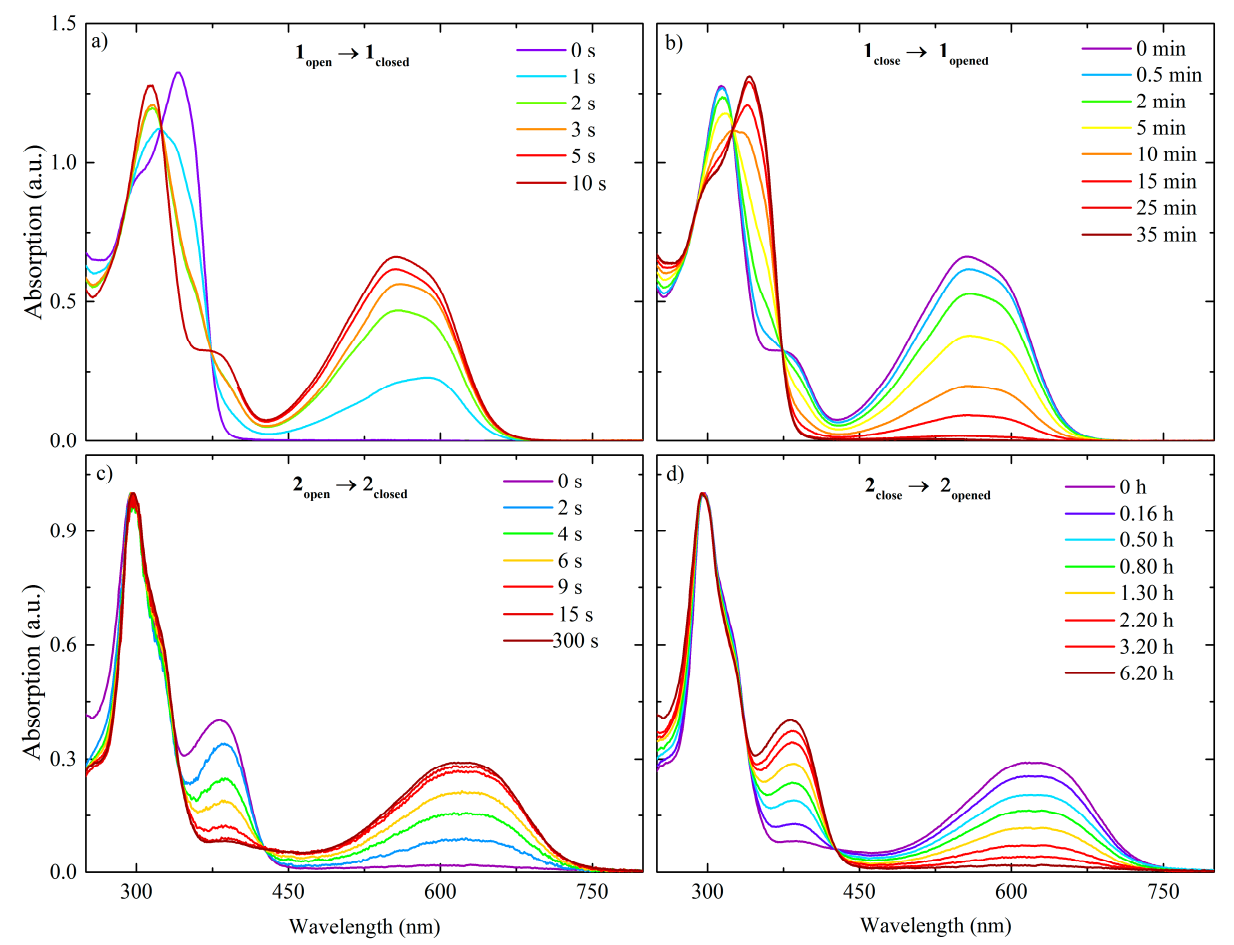

Figure 4. UV-Vis spectra for the photo-isomerisation (a) from $\boldsymbol{1}_{\text {open }}$ to $\boldsymbol{1}_{\text {close, }}$ (b) from $\boldsymbol{1}_{\text {close }}$ to $\boldsymbol{1}_{\text {open }}$, (c) from $\boldsymbol{2}_{\text {open }}$ to $\boldsymbol{2}_{\text {close }}$ and (d) from $\boldsymbol{2}_{\text {close }}$ to $\boldsymbol{2}_{\text {open }}$ isomerization.

The photo-isomerization from $\boldsymbol{2}_{\text {open }}$ to $\boldsymbol{2}_{\text {close }}$ took place within $10 \mathrm{~s}$, whereas the reverse ring-opening reaction needed more than $4 \mathrm{~h}$ to complete. The electron-withdrawing effects of the $\mathrm{Dy}(\mathrm{hfac})_{3}$ units when the ligand is fully conjugated is thought to be the reason for the longer time needed for the complex to return to its open form, as compared to the free ligand.

Photoisomerization in the solid state was not observed.

\subsection{Magnetic Properties}

The magnetic susceptibilities $(\chi)$ of polycrystalline samples of $\mathbf{2}_{\text {open }}$ and $\mathbf{2}_{\text {close }}$ were measured (Figure S3). The $\chi T$ values at room temperature of 28.25 and $27.98 \mathrm{~cm}^{3} \cdot \mathrm{K} \cdot \mathrm{mol}^{-1}$ for $2_{\text {open }}$ and 
$\mathbf{2}_{\text {close}}$, respectively, agree with the expected value for two free Dy ions $\left(28.34 \mathrm{~cm}^{3} \cdot \mathrm{K} \cdot \mathrm{mol}^{-1}\right)$ [17], and decreased continuously with a decrease in $T$, becoming 22.45 and $21.5 \mathrm{~cm}^{3} \cdot \mathrm{K} \cdot \mathrm{mol}^{-1}$ for $2_{\text {open }}$ and $\mathbf{2}_{\text {close}}$, respectively, at $2 \mathrm{~K}$. For both complexes, this decrease in the $\chi T$ values was attributed to the depopulation of the $m_{J}$ sub-levels of the ground state. The difference in the depopulation rate can be explain by different energy splittings of the $m_{J}$ sub-levels for the two complexes due to the slightly different crystal fields around the Dy ions $\left(D_{2 d}\right.$ for $\mathbf{2}_{\text {open }}$ and $D_{4 d}$ for $\left.\mathbf{2}_{\text {close }}\right)$. Anti-ferromagnetic interactions between the ions is not a suitable explanation for this decrease in $\chi T$ due to the long intra- $(\approx 17 \AA)$ and intermolecular $(\approx 9 \AA)$ distances.

$M$ vs. $H$ curves measured for $\boldsymbol{2}_{\text {open }}$ and $\boldsymbol{2}_{\text {close }}$ at $1.82 \mathrm{~K}$ are slightly different. Both showed pseudo saturation from $1 \mathrm{~T}$ with a slope of 0.276 and $0.199 \mathrm{~N} \beta \mathrm{T}^{-1}$ for $\mathbf{2}_{\text {open }}$ and $\mathbf{2}_{\text {close }}$, respectively. $M$ values of 10.48 and $9.62 \mathrm{~N} \beta$ at $5 \mathrm{~T}$ for $\boldsymbol{2}_{\text {open }}$ and $\boldsymbol{2}_{\text {close, }}$, respectively, was obtained. The difference in magnetization for both complexes confirms the presence of different ground states for the two complexes. Hysteresis loops were not observed for both complexes.

The dynamic $\chi$ measurement in the absence of external magnetic field shows an out of range, out-of-phase signal $\left(\chi^{\prime \prime}\right)$ in the high frequency region for both complexes (Figure S4a,b). Analyses by using Cole-Cole model [18] (Figure S5) and the complete model equation [19] revealed that $\mathbf{2}_{\text {close }}$ underwent an Orbach/QTM relaxation process (Table S3). $\mathbf{2}_{\text {open }}$ only underwent two Orbach processes. Nevertheless, since the maximum of $\chi^{\prime \prime}$ was out of range, the extracted relaxation time will not be accurate, and the actual relaxation mechanism may be unclear. In order to confirm the existence of QTM and to suppress it, an optimum static field of 1000 Oe was applied (Figure S6a,b). In this field, both complexes show a single relaxation process with the maxima of $\chi^{\prime \prime}$ shifted to a lower frequency region compared to that without static field (Figure 5a,b), and the relaxation process was determined to be a combination of a direct/Raman for $\mathbf{2}_{\text {open }}$ and a direct/Orbach for $\mathbf{2}_{\text {close }}$.
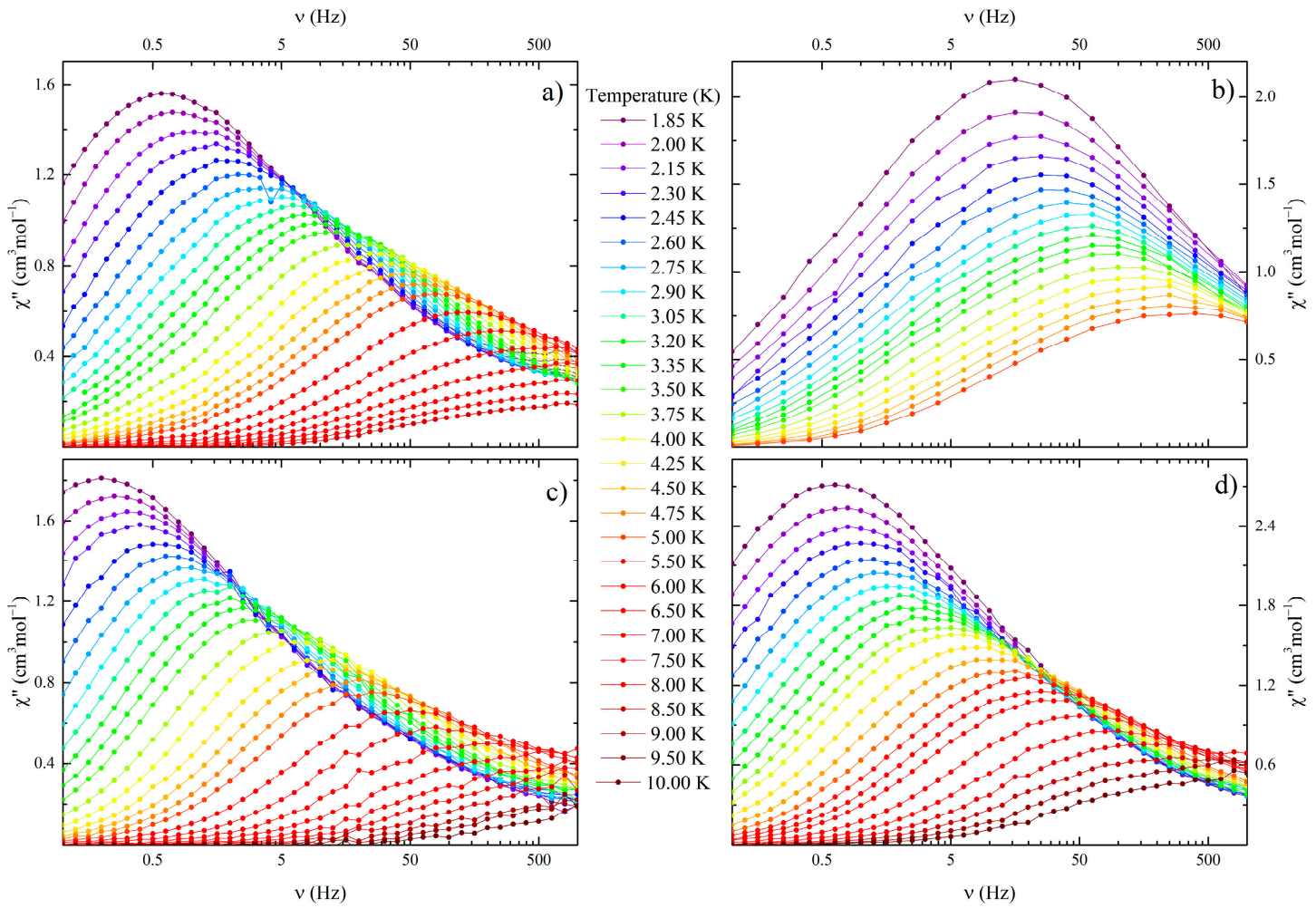

Figure 5. $T$ and $v$ dependences of $\chi^{\prime \prime}$ in $(\mathbf{a}, \mathbf{b})$ the solid state and $(\mathbf{c}, \mathbf{d})$ solution state for $\mathbf{2}_{\text {open }}$ and $\mathbf{2}_{\text {close }}$ respectively in a 1000 Oe magnetic field. 
In order to determine more precisely the role of the DTE ligand in the relaxation mechanism of the complexes, the magnetic properties were measured in a frozen dichloromethane solution (Figures S4c,d, S5, S6c,d and 5c,d). In the frozen solution, each complex molecule was considered to be isolated without any packing effects on the coordination geometry of the Dy ions. Without an external

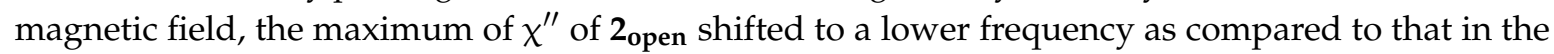
solid state, whereas the $\chi^{\prime \prime}$ of $\mathbf{2}_{\text {close }}$ did not change. The magnetisations of both complexes undergo an Orbach/QTM relaxation mechanism with a small energy barrier $\left(<10 \mathrm{~cm}^{-1}\right)$ (Table S3). In a $1000 \mathrm{Oe}$ magnetic field, the maximum of $\chi^{\prime \prime}$ of both complexes shifted to a lower frequency as compared to that of the solid state, meaning that a direct/Raman relaxation process occurred for both complexes.

The relaxation times in the solution state were determined using the Havriliak-Negami model [20], instead of the classical Cole-Cole model. Due to the asymmetry of the relaxation signal, the Cole-Cole model was not able to fit correctly the data and the Havriliak-Negami have been used to solve this problem. The asymmetry can also be observed on the Cole-Cole plot (Figures S7 and S8). A similar behaviour have been observed in our previous solution measurements [19].

\section{Discussion}

As we previously reported [21], the crystal structure and constraints on the coordination sphere play significant roles in the photo-isomerisation of the complexes. In this study, we show that crystal packing also play a role in the photo-isomerisation. The presence of a crystal solvent molecule close to the DTE core in $\mathbf{2}_{\text {open }}$ prevents the cyclization of the ligand due to steric hindrance. For $\mathbf{2}_{\text {close }}$ the crystal solvent and $\pi-\pi$ interaction block ring opening. Furthermore, isomerization of the complexes induces large molecular rearrangements, which are restricted by the crystal packing. Single-crystal to single-crystal transformation is not possible for these complexes. This was confirmed since we were able to follow the isomerization by UV-Visible spectroscopy in solution but not in the solid state. In solution, previously mentioned restraints are removed, and photo-isomerisation can be observed.

Although isomerisation does not occur in the solid state, the form of the DTE ligand seems to play a role in the magnetic relaxation process of the Dy ions. Both in the solid and solution states, the complex with closed form of the DTE ligand underwent faster magnetic relaxation than the complex with the open form of the DTE ligand. Similar behaviour has been reported in our previous work involving an Mn(salen) SMM bridged by a DTE ligand [8]. The closed form of the ligand is fully conjugated from one coordination site to the other one, whereas the open form does not have such conjugation. Therefore, conjugation increases the electronic interactions between the Dy ions in the closed form. Although the form of the ligand plays an important role in the magnetic properties, how the change in conjugation of the ligand and the change in the electronic interactions affect the magnetic relaxation mechanism pathway (i.e., direct, Raman, Orbach) remain unclear.

\section{Materials and Methods}

All chemicals and solvents used in this study were obtained from Sigma Aldrich, Tokyo Chemical Industry, Strem or Wako Chemicals GmbH. Synthesis of 1,2-bis(5-chloro-2-methylthiophen-3-yl)cyclopent-1-ene and $\mathrm{Dy}(\mathrm{hfac})_{3} \cdot 2 \mathrm{H}_{2} \mathrm{O}$ was performed following a previously reported procedure [22,23].

All synthesis and characterizations of the closed form of the ligand and complex was performed under dark conditions to avoid isomerisation to the open form.

\subsection{Synthesis of $\mathbf{1}_{\text {open }}$}

To a solution of 1,2-bis(5-chloro-2-methylthiophen-3-yl)cyclopent-1-ene (988 mg, $3 \mathrm{mmol}$ ) and dry tetrahydrofuran $(15 \mathrm{~mL})$ under a nitrogen atmosphere cooled in an ice bath, $2.6 \mathrm{M} \mathrm{n}$-BuLi $(2.96 \mathrm{~mL}$, $6.6 \mathrm{mmol})$ was slowly added over $1 \mathrm{~h}$ to give a dark-pink mixture. Then tris- $n$-butylborate $(2.07 \mathrm{~g}$, $2.42 \mathrm{~mL}, 9 \mathrm{mmol}$ ) was added, and the resulting orange solution was allowed to warm up to room temperature and stirred for $1 \mathrm{~h}$. Next, $\mathrm{Pd}\left(\mathrm{PPh}_{3}\right)_{4}(200 \mathrm{mg}, 5 \mathrm{~mol} \%$,) was suspended in tetrahydrofuran 
$(15 \mathrm{~mL})$ and heated to $70{ }^{\circ} \mathrm{C}$. After $30 \mathrm{~min}$, aqueous $2.5 \mathrm{M} \mathrm{K}_{2} \mathrm{CO}_{3}(30 \mathrm{~mL})$, ethylene glycol (10 drops), and 5-bromo-2,2'-bipyridine $(1.55 \mathrm{~g}, 6.6 \mathrm{mmol})$ were added. This reaction mixture was slowly added to the first solution. The combined solution was heated at $70{ }^{\circ} \mathrm{C}$ for $24 \mathrm{~h}$ and then cooled to room temperature, followed by addition of water $(20 \mathrm{~mL})$. The crude product was extracted with diethyl ether, the combined organic phases were dried over anhydrous $\mathrm{Na}_{2} \mathrm{SO}_{4}$, and the solvent was removed. Pure violet solid $\mathbf{1}_{\text {open }}$ was obtained by using column chromatography on $\mathrm{SiO}_{2}(4: 1 v / v$ hexane:ethyl-acetate), followed by a recrystallization from the same solvents, in $35 \%$ yield. ${ }^{1} \mathrm{H}$ NMR $\left(500 \mathrm{MHz}, \mathrm{CDCl}_{3}\right): \delta=2.07\left(6 \mathrm{H}, \mathrm{s}, \mathrm{ArCH}_{3}\right), 2.12\left(2 \mathrm{H}, \mathrm{m}, \mathrm{ArCH}_{2} \mathrm{CH}_{2}\right), 2.88\left(4 \mathrm{H}, \mathrm{t}, J=7.5 \mathrm{~Hz}, \mathrm{ArCH}_{2} \mathrm{CH}_{2}\right)$, $7.15(2 \mathrm{H}, \mathrm{s}, \mathrm{ArH}), 7.29(2 \mathrm{H}, \mathrm{ddd}, J=7.4,4.8,1.0 \mathrm{~Hz}, \mathrm{ArH}), 7.80(2 \mathrm{H}, \mathrm{td}, J=7.8,1.7 \mathrm{~Hz}, \mathrm{ArH}), 7.88(2 \mathrm{H}$, $\mathrm{dd}, J=8.3,2.4 \mathrm{~Hz}, \mathrm{ArH}), 8.38(4 \mathrm{H}, \mathrm{dd}, J=7.8,6.6 \mathrm{~Hz}, \mathrm{ArH}), 8.67(2 \mathrm{H}, \mathrm{d}, J=4.8 \mathrm{~Hz}, \operatorname{ArH}), 8.82(2 \mathrm{H}, \mathrm{d}$, $J=1.9 \mathrm{~Hz}, \mathrm{ArH})$.

\subsection{Synthesis of $\mathbf{2}_{\text {open }}$}

Dy $(\mathrm{hfac})_{3} \cdot 2 \mathrm{H}_{2} \mathrm{O}(24.5 \mathrm{mg}, 0.03 \mathrm{mmol})$ was dissolved in boiling heptane $(10 \mathrm{~mL})$. After cooling down to $60^{\circ} \mathrm{C}$, a dichloromethane solution $(5 \mathrm{~mL})$ of $\mathbf{1}_{\text {open }}(8.5 \mathrm{mg}, 0.015 \mathrm{mmol})$ was added, and the solution was stirred at room temperature for $10 \mathrm{~min}$. Slow evaporation of the solvent at room temperature for $24 \mathrm{~h}$ afforded green sheet-like crystals of $\mathbf{2}_{\text {open, }}$ suitable for single crystal X-ray diffraction. Yield: $60 \%(20 \mathrm{mg})$.

\subsection{Synthesis of $\mathbf{2}_{\text {close }}$}

$\mathbf{1}_{\text {open }}(8.5 \mathrm{mg}, 0.015 \mathrm{mmol})$ was first dissolved in dichloromethane $(7 \mathrm{~mL})$ and irradiated with $365 \mathrm{~nm}$ light for an hour to form $\mathbf{1}_{\text {close }}$. Dy $(\mathrm{hfac})_{3} \cdot 2 \mathrm{H}_{2} \mathrm{O}(24.5 \mathrm{mg}, 0.03 \mathrm{mmol})$ was dissolved in boiling heptane $(10 \mathrm{~mL})$. After cooling down to $60{ }^{\circ} \mathrm{C}$, the solution of $\mathbf{1}_{\text {close }}$ was added and stirred at room temperature for $10 \mathrm{~min}$. Slow evaporation of the solvent at room temperature for a few days gave black block like crystals of $\mathbf{2}_{\text {close, }}$ suitable for single crystal X-ray diffraction. Yield: $35 \%(10 \mathrm{mg})$.

\subsection{Single-Crystal X-ray Diffraction}

Single-crystal X-ray diffraction data of $\mathbf{2}_{\text {open }}$ was collected on a Bruker APEX-II diffractometer with an Bruker Photon 100 CMOS detector and a Cryo system DX-CS190LD (JAPAN thermal Engineering Co., Ltd., Tokyo, Japan). Single-crystal crystallographic data of $\boldsymbol{2}_{\text {close }}$ was collected on a Rigaku Saturn70 CCD diffractometer (Rigaku, Tokyo, Japan) with graphite-monochromated Mo $K \alpha$ radiation $(\lambda=0.71075 \AA$ ) produced by a VariMax micro-focus $X$-Ray rotating anode source at $90 \mathrm{~K}$. Data processing was performed using the CrystalClear crystallographic software package [24]. For both complexes, the structures were solved by using direct methods via SIR [25], and refinement were carried out using SHELXL-2014 [26]. The non-H atoms were refined anisotropically as possible using weighted full-matrix least-squares on $F^{2}$. $\mathrm{H}$ atoms attached to the $\mathrm{C}$ atoms were positioned using idealized geometries and refined using a riding model.

CCDC Nos. 1586166-1586167 contains the supplementary crystallographic data for complexes (See Supplementary Materials). These data can be obtained free of charge via http:/ / www.ccdc.cam. ac.uk/conts/retrieving.html, or from the Cambridge Crystallographic Data Centre, 12 Union Road, Cambridge CB2 1EZ, UK; fax: (+44) 1223-336-033; or e-mail: deposi@@ccdc.cam.ac.uk.

\subsection{Physical Measurements}

UV-Vis absorption spectra were acquired in $\mathrm{CH}_{2} \mathrm{Cl}_{2}$ solution on a Shimadzu UV-3150 spectrophotometer (Shimadzu, Tokyo, Japan). Compounds were irradiated for different amounts of time with a UV light at $365 \mathrm{~nm}$ to isomerise from open to close forms and with a visible light at $490 \mathrm{~nm}$ to isomerise from close to open forms. Photo-isomerization was performed with a $300 \mathrm{~W}$ Xenon Light Source Asahi Spectra MAX-303 (Asahi, Tokyo, Japan).

Magnetic susceptibility measurements were performed on solid polycrystalline samples on a Quantum Design MPMS-XL SQUID magnetometer (Quantum Design, San Diego, CA, USA). 
The experimental data were corrected for the diamagnetism of the sample holder, and the intrinsic diamagnetism of the materials was evaluated using Pascal's tables [27]. Ac measurements were performed in a 3 Oe oscillating magnetic field with and without a static dc field. For the solution state magnetic measurements, the masses of the sample and the solvent were measured after the measurement and confirmed with the values by the MH curve in solid and solution states [28].

\section{Conclusions}

A new DTE bridged bipyridine ligand was synthesized in its open and close forms. Dy ions were coordinated to this ligand to form a photosensitive dinuclear complex, which have been structurally, optically and magnetically characterized by using single X-ray diffraction, UV-Visible absorption spectroscopy and static and dynamic magnetometry. Although photo-isomerisation of complexes in the solid state was not possible due to presence of strong $\pi-\pi$ interactions and a crystal solvent molecule, in the solution state, photo-isomerisation was observed. The ring-opening process was around 1500 times slower than the closing one was. Furthermore, the closed form of the ligand, which is fully conjugated, induced faster relaxation of the magnetization than the open form did in both solution and solid states. We are currently studying the effects of the ligand form on the relaxation mechanism pathway.

Supplementary Materials: The following are available online at www.mdpi.com/2304-6740/6/1/9/s1. Cif and cif-checked files, Table S1: Summary of the crystal parameters for $\mathbf{2}_{\text {open }}$ and $\mathbf{2}_{\text {close }}$; Table S2: deviation from the idealized coordination geometries obtained by using SHAPE 2.1. Lowest value is better; Figure S1: (a) top, (b) front and (c) side views of the interactions between the DTE ligand and the heptane solvent molecule in 2open; Figure S2: (a) top, (b) front and (c) side views of the interactions between the DTE ligand and the heptane solvent molecule in $\mathbf{2}_{\text {close; }}$ Figure S3: T dependence of $\chi T$ for $\mathbf{2}_{\text {open }}$ and $\mathbf{2}_{\text {close }}$ and the field dependence of the magnetization at $1.82 \mathrm{~K}$ in inset; Figure S4: T and $v$ dependences of $\chi^{\prime \prime}$ in $(\mathbf{a}, \mathbf{b})$ the solid state and (c,d) solution state, for $\mathbf{2}_{\text {open }}$ and $\mathbf{2}_{\text {close }}$, respectively, in a 0 Oe magnetic field; Figure S5: Arrhenius plots with best-fit curves (lines).; Figure S6: $\mathrm{H}$ and $v$ dependences of $\chi^{\prime \prime}$ in $(\mathbf{a}, \mathbf{b})$ the solid state and (c,d) solution state for $\mathbf{2}_{\text {open }}$ and $\mathbf{2}_{\text {close, }}$ respectively, at $1.85 \mathrm{~K}$; Table S3: Summary of the fitting parameters for the complete model.; Table S4: Fitting parameters for the Cole-Cole model for the frequency dependence of $\chi$ of $\boldsymbol{2}_{\text {open }}$ in the solid state in a 0 Oe field. $\chi_{\text {adia }}$ was fixed at 0 ; Table S5: Fitting parameters for the two relaxation Cole-Cole model for the frequency dependence of $\chi$ of $\mathbf{2}_{\text {open }}$ in the solid state in a 1000 Oe field. $\chi_{\text {adia }}$ was fixed at 0; Table S6: Fitting parameters for the Cole-Cole model for the frequency dependence of $\chi^{\prime \prime}$ of $\mathbf{2}_{\text {close }}$ in the solid state in a 0 Oe field; Table S7: Fitting parameters for the Havriliak-Negami model for the frequency dependence of $\chi^{\prime \prime}$ of $\boldsymbol{2}_{\text {close }}$ in the solid state in a 1000 Oe field; Table S8: Fitting parameters for the Havriliak-Negami model for the frequency dependence of $\chi^{\prime \prime}$ of $2_{\text {open }}$ in the solution state in a 1000 Oe field. $X_{\text {adia }}$ was fixed at 0; Table S9: Fitting parameters for the Havriliak-Negami model for the frequency dependence of $\chi^{\prime \prime}$ of $\mathbf{2}_{\text {open }}$ in the solution state in a 1000 Oe field. Table S10: Fitting parameters for the Cole-Cole model for the frequency dependence of $\chi^{\prime \prime}$ of $\boldsymbol{2}_{\text {close }}$ in the solution state in a 0 Oe field; Table S11: Fitting parameters for the Havriliak-Negami model for the frequency dependence of $\chi^{\prime \prime}$ of $\boldsymbol{2}_{\text {close }}$ in the solution state in a 1000 Oe field.

Acknowledgments: The authors wish to thank the Japan International Cooperation Agency (JICA) for the scholarship of Mritunjoy Kamila.

Author Contributions: Goulven Cosquer and Mritunjoy Kamila conceived and designed the experiments; Mritunjoy Kamila performed the experiments and Zhao-Yang Li performed the DTE ligand synthesis; Mritunjoy Kamila and Zhao-Yang Li performed the optical property study; Goulven Cosquer analyzed the data; Goulven Cosquer and Brian K. Breedlove wrote the paper. Masahiro Yamashita supervised and managed the project.

Conflicts of Interest: The authors declare no conflict of interest.

\section{References}

1. Komeda, T.; Isshiki, H.; Liu, J.; Zhang, Y.-F.; Lorente, N.; Katoh, K.; Breedlove, B.K.; Yamashita, M. Observation and Electric Current Control of a Local Spin in a Single-Molecule Magnet. Nat. Commun. 2011, 2, 217. [CrossRef] [PubMed]

2. Zhou, Q.; Yang, F.; Xin, B.; Zeng, G.; Zhou, X.; Liu, K.; Ma, D.; Li, G.; Shi, Z.; Feng, S. Reversible Switching of Slow Magnetic Relaxation in a Classic Lanthanide Metal-Organic Framework System. Chem. Commun. 2013, 49, 8244-8246. [CrossRef] [PubMed] 
3. Liu, J.-L.; Chen, Y.-C.; Zheng, Y.-Z.; Lin, W.-Q.; Ungur, L.; Wernsdorfer, W.; Chibotaru, L.F.; Tong, M.-L. Switching the Anisotropy Barrier of a Single-Ion Magnet by Symmetry Change from Quasi- $D_{5 \mathrm{~h}}$ to Quasi- $O_{\mathrm{h}}$. Chem. Sci. 2013, 4, 3310-3316. [CrossRef]

4. $\quad$ Feng, X.; Mathonière, C.; Jeon, I.-R.; Rouzières, M.; Ozarowski, A.; Aubrey, M.L.; Gonzalez, M.I.; Clérac, R.; Long, J.R. Tristability in a Light-Actuated Single-Molecule Magnet. J. Am. Chem. Soc. 2013, 135, 15880-15884. [CrossRef] [PubMed]

5. Kuch, W. Magnetic Nanostructures: Edge Atoms Do All the Work. Nat. Mater. 2003, 2, 505-506. [CrossRef] [PubMed]

6. Thirion, C.; Wernsdorfer, W.; Mailly, D. Switching of Magnetization by Nonlinear Resonance Studied in Single Nanoparticles. Nat. Mater. 2003, 2, 524-527. [CrossRef] [PubMed]

7. Gütlich, P.; Garcia, Y.; Woike, T. Photoswitchable Coordination Compounds. Coord. Chem. Rev. 2001, 219, 839-879. [CrossRef]

8. Fetoh, A.; Cosquer, G.; Morimoto, M.; Irie, M.; El-Gammal, O.; El-Reash, G.A.; Breedlove, B.K.; Yamashita, M. Photo-Activation of Single Molecule Magnet Behavior in a Manganese-Based Complex. Sci. Rep. 2016, 6, 23785. [CrossRef] [PubMed]

9. Morimoto, M.; Miyasaka, H.; Yamashita, M.; Irie, M. Coordination Assemblies of $\left[\mathrm{Mn}_{4}\right]$ Single-Molecule Magnets Linked by Photochromic Ligands: Photochemical Control of the Magnetic Properties. J. Am. Chem. Soc. 2009, 131, 9823-9835. [CrossRef] [PubMed]

10. Shiga, T.; Miyasaka, H.; Yamashita, M.; Morimoto, M.; Irie, M. Copper(II)-terbium(III) Single-Molecule Magnets Linked by Photochromic Ligands. Dalt. Trans. 2011, 40, 2275-2282. [CrossRef] [PubMed]

11. Pinkowicz, D.; Ren, M.; Zheng, L.-M.; Sato, S.; Hasegawa, M.; Morimoto, M.; Irie, M.; Breedlove, B.K.; Cosquer, G.; Katoh, K.; et al. Control of the Single-Molecule Magnet Behavior of Lanthanide-Diarylethene Photochromic Assemblies by Irradiation with Light. Chem. Eur. J. 2014, 20, 12502-12513. [CrossRef] [PubMed]

12. Cosquer, G.; Morimoto, M.; Irie, M.; Fetoh, A.; Breedlove, B.K.; Yamashita, M. Photo-Control of the Magnetic Properties of Dy(III) and Ho(III) Homometal Coordination Polymers Bridged by a Diarylethene Ligand. Dalt. Trans. 2015, 44, 5996-6002. [CrossRef] [PubMed]

13. Kobatake, S.; Uchida, K.; Tsuchida, E.; Irie, M. Single-Crystalline Photochromism of Diarylethenes: Reactivity-Structure Relationship. Chem. Commun. 2002, 2, 2804-2805. [CrossRef]

14. Alvarez, S.; Alemany, P.; Casanova, D.; Cirera, J.; Llunell, M.; Avnir, D. Shape Maps and Polyhedral Interconversion Paths in Transition Metal Chemistry. Coord. Chem. Rev. 2005, 249, 1693-1708. [CrossRef]

15. Ruiz-Martínez, A.; Casanova, D.; Alvarez, S. Polyhedral Structures with an Odd Number of Vertices: Nine-Coordinate Metal Compounds. Chem. Eur. J. 2008, 14, 1291-1303. [CrossRef] [PubMed]

16. Guerchais, V.; Ordronneau, L.; Le Bozec, H. Recent Developments in the Field of Metal Complexes Containing Photochromic Ligands: Modulation of Linear and Nonlinear Optical Properties. Coord. Chem. Rev. 2010, 254, 2533-2545. [CrossRef]

17. Kahn, O. Molecular Magnetism; Wiley-VCH: New York, NY, USA, 1993.

18. Cole, K.S.; Cole, R.H. Dispersion and Absorption in Dielectrics I. Alternating Current Characteristics. J. Chem. Phys. 1941, 9, 341. [CrossRef]

19. Pedersen, K.S.; Ungur, L.; Sigrist, M.; Sundt, A.; Schau-magnussen, M.; Vieru, V.; Mutka, H.; Rols, S.; Weihe, H.; Waldmann, O.; et al. Modifying the Properties of 4f Single-Ion Magnets by Peripheral Ligand Functionalisation. Chem. Sci. 2014, 5, 1650-1660. [CrossRef]

20. Havriliak, S.; Negami, S. A Complex Plane Representation of Dielectric and Mechanical Relaxation Processes in Some Polymers. Polymer 1967, 8, 161-210. [CrossRef]

21. Kamila, M.; Cosquer, G.; Breedlove, B.K.; Yamashita, M. Packing Structure Effects on the Slow Magnetic Relaxation Pathways of Dysprosium (III) Complexes. Bull. Chem. Soc. Jpn. 2017, 90, 595-603. [CrossRef]

22. Morimoto, M.; Irie, M. Photochromic Reactions of Diarylethenes in Single Crystals with Intermolecular O-H $\cdots$ N Hydrogen-Bonding Networks. Chem. Eur. J. 2006, 12, 4275-4282. [CrossRef] [PubMed]

23. Richardson, M.F.; Wagner, W.F.; Sands, D.E. Rare-Earth Trishexafluoroacetylacetonates and Related Compounds. J. Inorg. Nucl. Chem. 1968, 30, 1275-1289. [CrossRef]

24. CrystalClear-SM, 1.4.0 SP1; Rigaku and Rigaku/MSC: The Woodlands, TX, USA, 2008. 
25. Altomare, A.; Burla, M.C.; Camalli, M.; Cascarano, G.L.; Giacovazzo, C.; Guagliardi, A.; Moliterni, A.G.; Polidori, G.; Spagna, R. SIR97: A New Tool for Crystal Structure Determination and Refinement. J. Appl. Crystallogr. 1999, 32, 115. [CrossRef]

26. Sheldrick, G. A Short History of SHELX. Acta Crystallogr. Sect. A 2008, 64, 112-122. [CrossRef] [PubMed]

27. Bain, G.A.; Berry, J.F. Diamagnetic Corrections and Pascal's Constants. J. Chem. Educ. 2008, 85, 532-536. [CrossRef]

28. Liang, Z.; Damjanović, M.; Kamila, M.; Cosquer, G.; Breedlove, B.K.; Enders, M.; Yamashita, M. Proton Control of the Lanthanoid Single-Ion Magnet Behavior of a Double-Decker Complex with an Indolenine-Substituted Annulene Ligand. Inorg. Chem. 2017, 56, 6512-6521. [CrossRef] [PubMed]

C 2018 by the authors. Licensee MDPI, Basel, Switzerland. This article is an open access article distributed under the terms and conditions of the Creative Commons Attribution (CC BY) license (http://creativecommons.org/licenses/by/4.0/). 